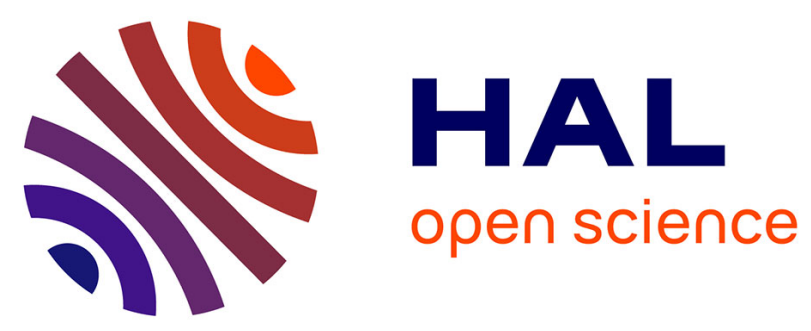

\title{
Phenomenological study of multivariable effects on exit burr criteria during orthogonal cutting of AlSi alloys using principal components analysis
}

Tristan Régnier, Guillaume Fromentin, Alain d'Acunto, José Outeiro, Bertrand Marcon, Arnaud Crolet

\section{To cite this version:}

Tristan Régnier, Guillaume Fromentin, Alain d'Acunto, José Outeiro, Bertrand Marcon, et al.. Phenomenological study of multivariable effects on exit burr criteria during orthogonal cutting of AlSi alloys using principal components analysis. Journal of Manufacturing Science and Engineering, 2018, 140 (10), pp.101006. 10.1115/1.4040623 . hal-01835810

\section{HAL Id: hal-01835810 https://hal.science/hal-01835810}

Submitted on 19 Dec 2018

HAL is a multi-disciplinary open access archive for the deposit and dissemination of scientific research documents, whether they are published or not. The documents may come from teaching and research institutions in France or abroad, or from public or private research centers.
L'archive ouverte pluridisciplinaire HAL, est destinée au dépôt et à la diffusion de documents scientifiques de niveau recherche, publiés ou non, émanant des établissements d'enseignement et de recherche français ou étrangers, des laboratoires publics ou privés. 


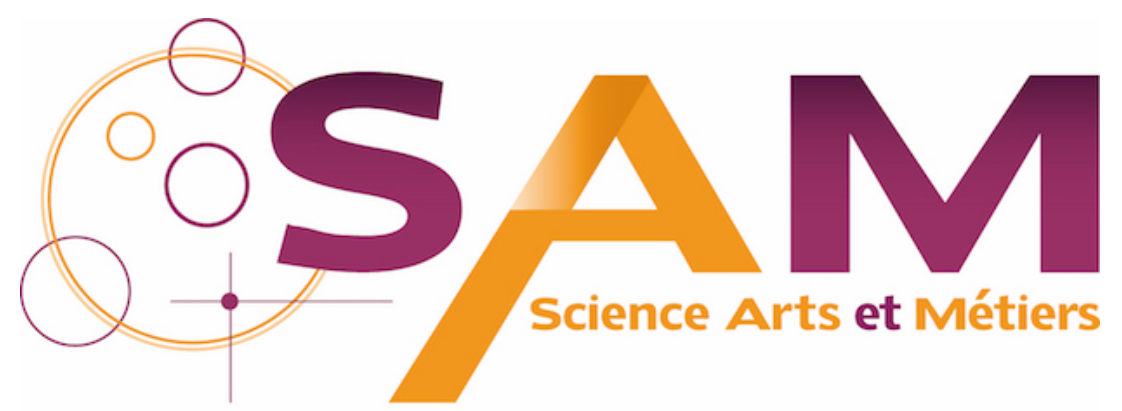

Archive Ouverte - Open Repository

\section{Science Arts \& Métiers (SAM)}

is an open access repository that collects the work of Arts et Métiers ParisTech researchers and makes it freely available over the web where possible.

This is an author-deposited version published in: https://sam.ensam.eu Handle ID: .http://hdl.handle.net/10985/13356

\section{To cite this version :}

Tristan RÉGNIER, Guillaume FROMENTIN, Alain D'ACUNTO, José OUTEIRO, Bertrand MARCON, Arnaud CROLET - Phenomenological study of multivariable effects on exit burr criteria during orthogonal cutting of AlSi alloys using principal components analysis - Journal of Manufacturing Science and Engineering - Vol. 140, n¹0, p.101006-1 - 101006-10 - 2018 


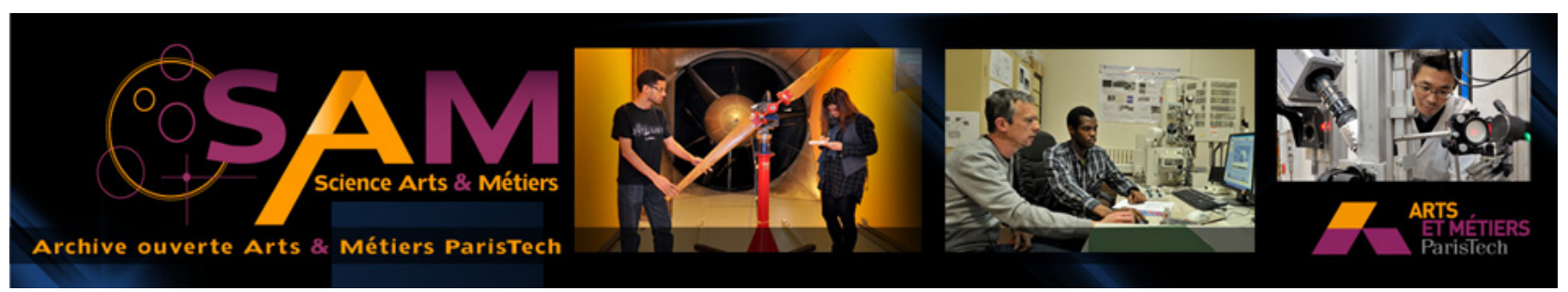

\section{Science Arts \& Métiers (SAM)}

is an open access repository that collects the work of Arts et Métiers ParisTech researchers and makes it freely available over the web where possible.

This is an author-deposited version published in: http://sam.ensam.eu

Handle ID: .http://hdl.handle.net/null

\section{To cite this version :}

Tristan RÉGNIER, Guillaume FROMENTIN, Alain D'ACUNTO, José OUTEIRO, Bertrand MARCON, Arnaud CROLET - Phenomenological study of multivariable effects on exit burr criteria during orthogonal cutting of AISi alloys using principal components analysis - Journal of Manufacturing Science and Engineering - Vol. 140, n¹0, p.10 - 2018 


\section{Phenomenological Study of Multivariable Effects on Exit Burr Criteria During Orthogonal Cutting of AISi Alloys Using Principal Components Analysis}

During machining, burrs are produced along a part's edges, which can affect a final product lifetime or its efficiency. Moreover, timeconsuming and expensive techniques are needed to be applied to remove such burrs. Therefore, companies attempt to reduce burrs formation during machining by manipulating the cutting conditions. This study aims to analyze and quantify the effect of a wide number of parameters on burr formation, resulting from different mechanisms, during orthogonal cutting of AlSi alloys. A highly developed experimental methodology combining high-speed camera recording, laser scanning, and in situ deburring system is used for this study. A statistical analysis is then applied to evaluate relations between controlled parameters and the occurrence of exit burrs morphologies. The results show that the uncut chip thickness influences burr types distribution along the exit edge and chamfer geometry. Among the cutting parameters and tool geometry, tool rake angle is the main parameter affecting burr height. Finally, it is found that none of the burrs geometrical characteristics ranges are piloted by cutting parameters or tool geometry. The assumption of a possible microstructural influence on these outputs is made.

[DOI: $10.1115 / 1.4040623$ ]

\author{
Tristan Régnier \\ LaBoMaP, \\ Arts et Métiers Paristech Cluny, \\ Rue porte de Paris, \\ Cluny 71250 , France \\ e-mail: tristan.regnier@ensam.eu
}

\author{
Guillaume Fromentin \\ Mem. ASME \\ LaBoMaP, \\ Arts et Métiers Paristech Cluny, \\ Rue porte de Paris, \\ Cluny 71250 , France \\ e-mail: guillaume.fromentin@ensam.eu
}

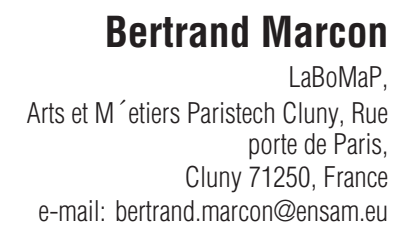

\author{
Alain D'Acunto \\ LEM3, \\ Arts et Métiers Paristech Metz, \\ 7 rue Félix Savart, \\ Metz 57073, France \\ e-mail: alain.dacunto@ensam.eu
}

\author{
José Outeiro \\ LaBoMaP, \\ Arts et Métiers Paristech Cluny, \\ Rue porte de Paris, \\ Cluny 71250 , France \\ e-mail: jose.outeiro@ensam.eu
}

Keywords: burr formation, statistical analysis, aluminum alloy, orthogonal cutting

\section{Introduction}

Machining operations such as milling or turning produce burrs along the parts edges. These burrs might affect a product's lifetime if they fall off after assembly or during a mechanical operation. Therefore, the presence of burrs on a finished part should be avoided. There are several types of deburring techniques but they are time consuming and expensive. Nowadays, companies aim to avoid or reduce burr formation by changing the cutting conditions (which includes tool geometry).

Machining operations induce several burr morphologies, grouped by Gillespie and Blotter [1] into four categories, with respect to their generation mode, as shown in Fig. 1. The Poisson burr is generated by a plastic flow of the work material toward the free surface and under compression. The rollover burr corresponds to an uncut material accumulation after each tool or tooth path, pushed along the cutting direction. The tear burr is the result of a tearing between two sections of a part. Finally, the cut-off burr is the small amount of material staying in the center of a workpiece after a cut-off operation. Pekelharing [2] and Iwata et al. [3] show that, at the end of a cut, fracture can occur at a workpiece's edge, generating a chamfer with a small burr. This burr is called by Hashimura et al. [4] as negative burr, as opposed to the rollover burr, which is called as positive burr.

The ISO 13715:2000 standard [5] proposes burr height to be measured from the exit surface of the workpiece to the top of the burr. This criterion is useful in industry but it is not sufficient to analyze accurately the burr shape and to investigate burr formation mechanisms. For a better burr characterization, Schäfer et al. [6] define a burr using five geometrical criteria associated with weighting factors to obtain a burr value. This burr value is then used as a comparison reference. However, some of these criteria need the use of destructive methods to be measured accurately and some burrs require more specific criteria for their comparisons. In a previous work, Régnier et al. [7] propose new geometrical criteria to define two types of burrs called burrs with or without chamfer, aiming to link the geometry of a burr with its formation mode in an AlSi fragile alloy. Those criteria are detailed in Fig. 2. The study proposes also to call them burrs with and without chamfer instead of the commonly used negative and positive burr. Furthermore, this definition is more relevant to the burr standard ISO definition.

These two types of burrs along the workpiece exit edge depend on the cutting conditions, such as the tool rake angle and the uncut 
chip thickness. According to Abushawashi [8], these two parameters affect the stress triaxiality in the workpiece deformation zone which lies ahead of the tool. This in turn affects the fracture strain since they are related. Figures $3(a)$ and $3(b)$ show the stress triaxiality distribution on both workpiece and cutting tool with respect to the rake angle. On the workpiece, the figures show that the increase of the rake angle leads to an increase of stress triaxiality on a zone between the cutting edge and a subsurface zone underneath the uncut surface (circled in the figures). The state of stress varies from a combined shear/tension, with approximate equal proportion for each (clear zone), to a quasi-pure tension (dark zone). This variation lowers the fracture strain in the region. On the other hand, Figs. 3(c) and 3(d) show the stress triaxiality distribution for two uncut chip thicknesses $(h)$. According to the figures, the increase of $h$ leads to the expansion of both combined shear/tension and almost pure shear zones and a shrinkage of combined shear/compression zone. In other words, a larger proportion (percentage) of the overall deformed material with low stress triaxiality state occurs in the low $h$. Finally, they show that with the same cutting condition, both burr types can be generated along the exit edge of the workpiece. This burr type heterogeneity could closely relate to the material microstructure heterogeneity.

Burr formation in face milling is widely studied by Chern [9]. The author analyzes the influence of feed rate and depth of cut on burr height and morphology for three aluminum alloys. Five burr morphologies are highlighted and their formation mechanisms are described, as presented in Fig. 4. The knife-type burrs, wave-type burrs, and curl-type burrs are all generated by the plastic bending of different volume of the material uncut transition surface. Those three types of burr are similar to the primary burrs defined by Kishimoto [10].

Increasing the depth of cut or the feed rate generates more plastic deformation during the bending of the transition surface material and breaks what could have been a primary burr, close to its root. This material fracture generates then a secondary burr, barely visible to naked eyes. Finally, if the depth of cut increases or the feed rate is too high, edge breakout (burr with chamfer formation) occurs. This formation mechanism is the same as the burr with chamfer formation in orthogonal cutting. The study also links the in-plane exit angle to the burr morphology. This angle, called $\varphi_{\mathrm{e}}$ in Fig. 5, is defined as the angle between the cutting speed direction and the workpiece exit surface. It is shown that both burr height and transition depth of cut (between primary and secondary burrs) increase with this angle. This angle appears to drive the primary burrs morphology as well. Bourlet et al. [11] study the influence of local geometrical parameters on burr height during high speed plane milling of a cast aluminum alloy. The authors show that the uncut chip thickness at the exit of an insert, the in-plane exit angle, the wedge angle $\Delta$ (angle that makes the exit surface with respect to the machined one, visible in Fig. 5), and the axial depth of cut were the main parameters driving burr height evolution. As such, a design of experiment is performed and a local prediction model is proposed.

Principal component analysis (PCA) is described by Abdi and Williams [12] as one of the oldest multivariate data analysis. Its aim is to find linear combinations, also known as principal components, of the initial variables. The data are then projected onto the principal components to extract their maximum variance. This method reduces considerably the dimension of the problem without altering the amount of information. The new orthogonal axes, obtained from the projection, are called principal axes. Moreover, the principal components are not correlated, as opposed to the original data, which may correlate. Therefore, results are being concluded objectively.

This analysis was first used mainly in nontechnical fields such as sociology or economy. It is first introduced in manufacturing by Lorenz [13], who describes the use of PCA to select the most suitable tap tool geometry and cutting conditions in terms of force reduction and thread surface quality. Nowadays, a few studies use hybrid approach combining the PCA with other statistical methods to optimize the efficiency of a production technique from design of experiment. For example, Dubey and Yadava [14] compare the optimized results of laser cutting of Inconel 718 using original Taguchi approach with a hybrid PCA/Taguchi method. (a)

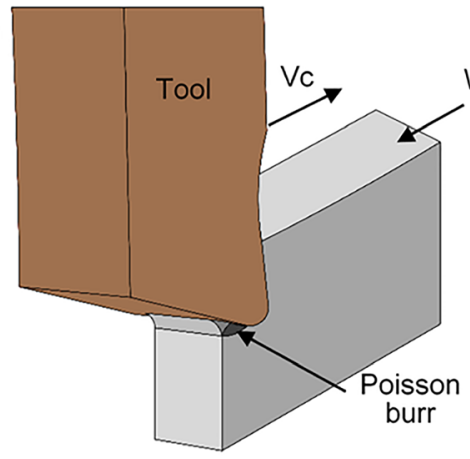

(c)

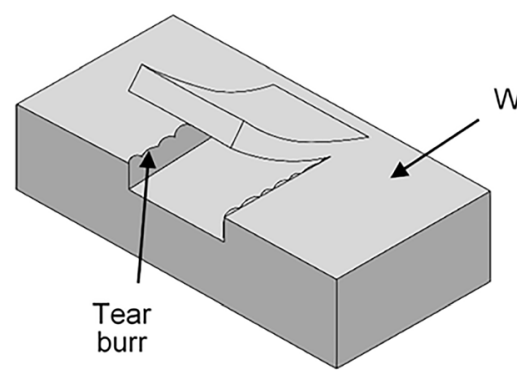

(b)

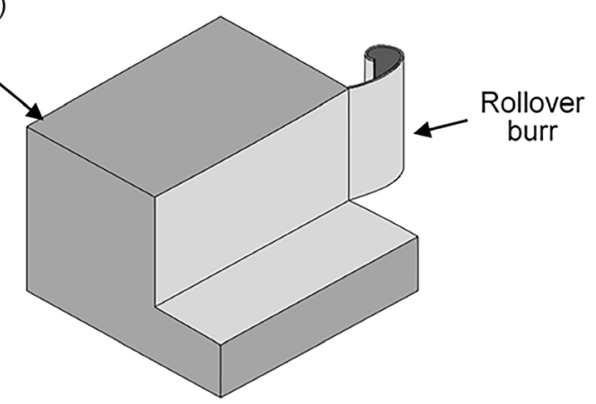

(d)

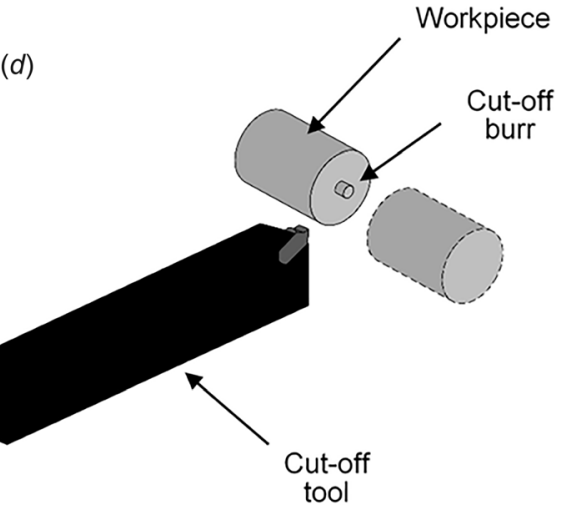

Fig. 1 Poisson burr (a), rollover burr (b), tear burr (c), and cut off burr ( $d$ ) (adapted from da Silva et al. [16] and Gillespie and Blotter [1]) 
The hybrid approach consists of determining the signal-to-noise ratios of three kerf quality characteristics using the Taguchi method and applying PCA on those ratios. Finally, the contribution of the input parameters on the kerf quality characteristics and the most suitable association between them are determined. It is found that the hybrid approach slightly provides a relatively better result.

In the current study, orthogonal cutting experiments are carried out on aluminum alloy samples. An original experimental setup including high-speed camera imaging, laser profile scanning of burr, and in situ deburring is used. It allows to observe burr formation and to characterize precisely the burr profile in hundreds of sections as well. Through this observation, the burr type heterogeneity can be quantified. A PCA is carried out using XLSTAT software. The use of PCA is proposed to analyze possible correlations between cutting parameters or tool geometry and a wide range of exit burr geometrical characteristics obtained during the experiments. Physical explanations, concluded from video analyses and full exit edge morphologies, are given to interpret the statistical analysis results.

\section{Experimental Procedure and Work Material}

2.1 Experimental Setup. Orthogonal cutting tests are conducted using a three-axes computer numerical control milling machine, DMG model DMC85V, equipped with linear motors. The cutting speed of $120 \mathrm{~m} / \mathrm{min}$ is provided by the $X$-axis of the machine. A high-speed CCD camera (PHOTRON SA-Z), visible in Fig. 6(a), is used to capture the burr formation during the tool exit from the workpiece. Its frame rate is set at $30,000 \mathrm{fps}$. A Mitutoyo objective assembled with extension lens tubes are used to perform a $10 \times$ magnification. The achieved observation window is of $1.835 \times 1.835 \mathrm{~mm}^{2}$ for a spatial resolution of approximately $1.8 \mu \mathrm{m} /$ pix. The forces are measured by a piezo-electric dynamometer, Kistler model 9119 AA2, presented in Fig. 6(b).

The procedure used to conduct the machining tests is described as follows. First, several cutting passes are performed to ensure that the machined surface is parallel to the cutting direction. Then the generated burrs during those previous operations are removed by a deburring cut. This operation is performed with a very (a)

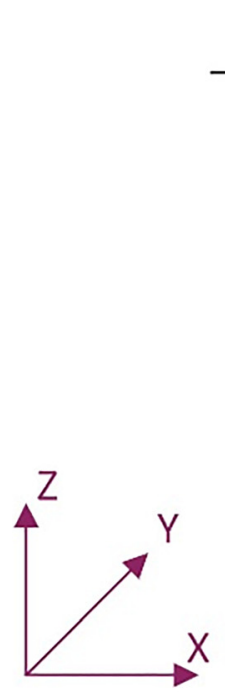

(c)

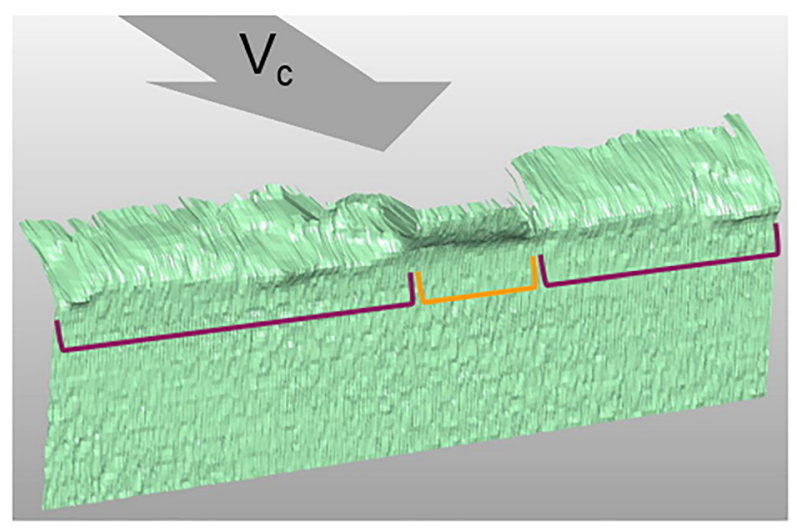

Burr with chamfer

$$
\begin{gathered}
\mathrm{Y}=0 \circ ; \mathrm{r}_{\beta}=20 \mu \mathrm{m} \\
\mathrm{h}=0.07 \mathrm{~mm}
\end{gathered}
$$

(b)

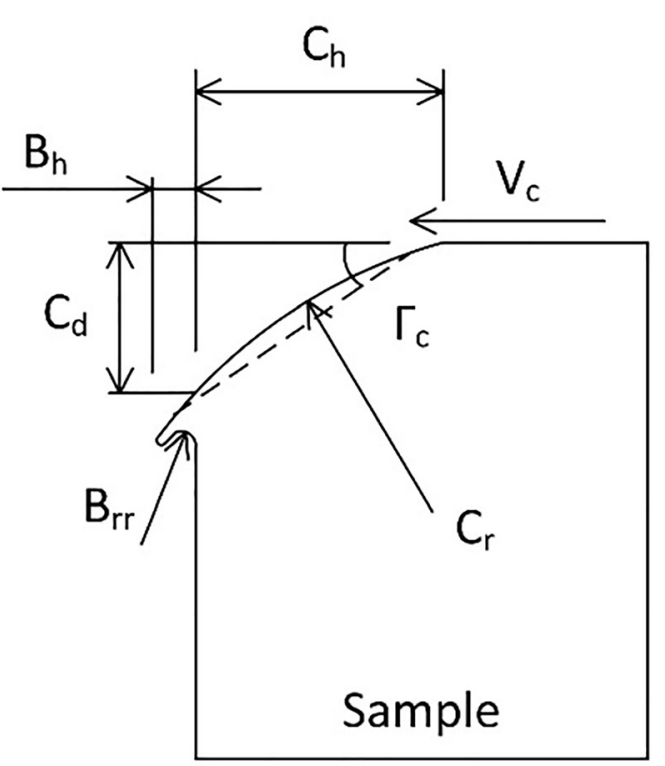

(d)

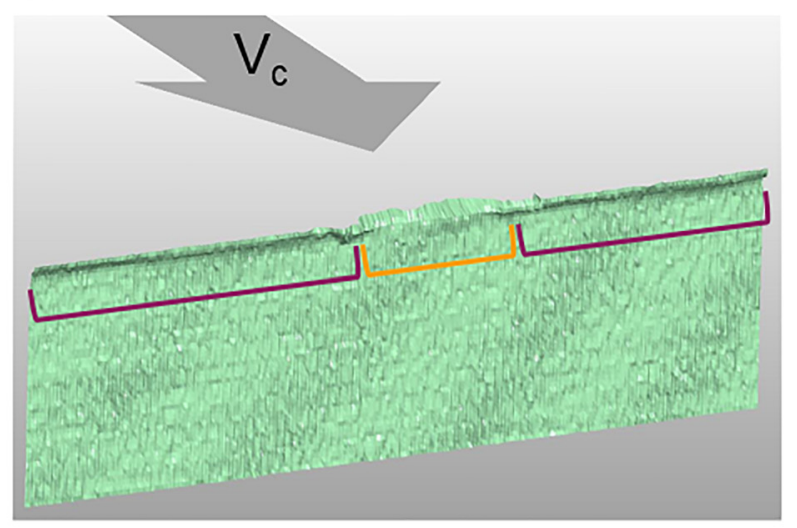

Fig. 2 Geometrical descriptors for (a) burr without chamfer, $(b)$ burr with chamfer and three-dimensional reconstruction of two samples' exit edges morphologies, exhibiting both burr types (c) and (d), after Régnier et al. [7] 

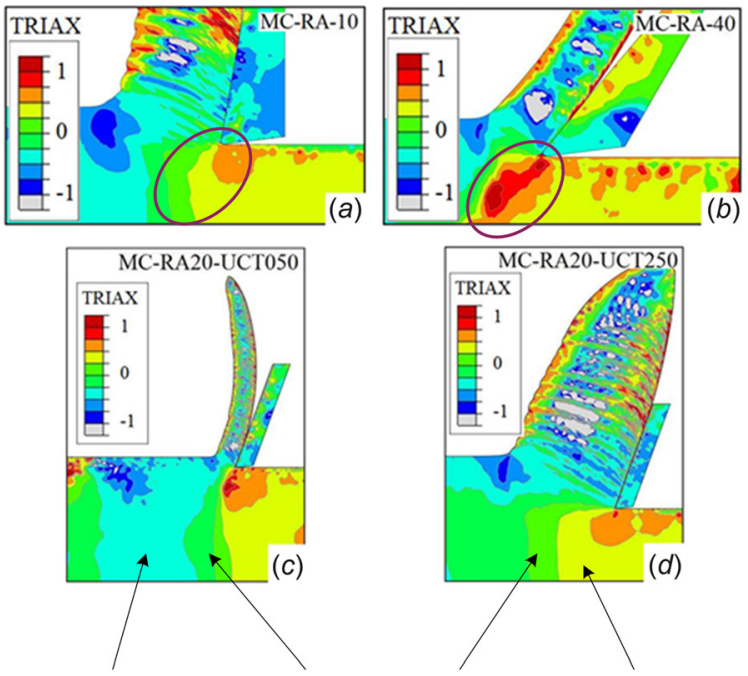

Combined shear/compression

Almost pure shear

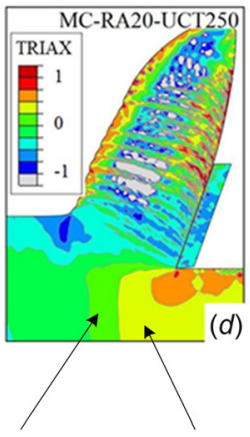

Combined shear/tension

Fig. 3 Influence of rake angle $(a)$ and $(b)$ and uncut chip thickness $(c)$ and $(d)$ on stress triaxiality distribution (from Abushawashi [8])

positive rake angle tool $(\gamma=30 \mathrm{deg})$, set on the opposite direction of the one used for the actual desired machining, as shown in Fig. 6(c). The deburring efficiency is verified several times during the whole test campaign. After that, the tests are performed according to an experimental sequence proposed in Fig. 7. Two cutting passes with every pass followed by a deburring cut are performed, as presented in Figs. 6(d) and 6(e). Three cutting passes are then performed without any deburring cut in between

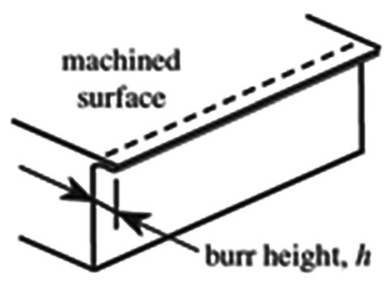

(a) knife-type burr

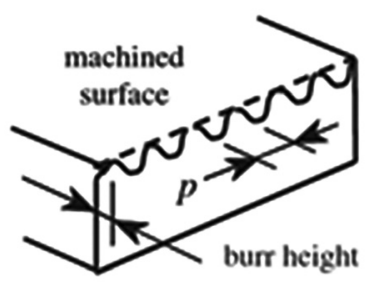

(c) wave-type burr

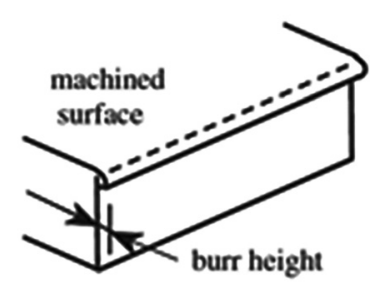

(b) curl-type burr

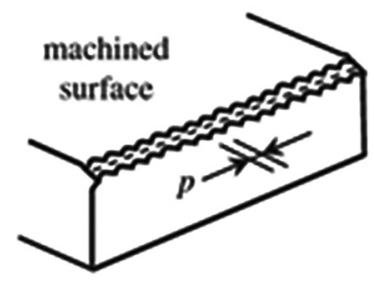

(d) edge breakout

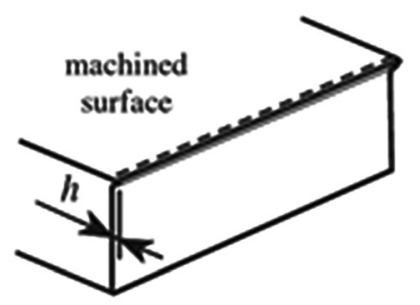

(e) secondary burr

Fig. 4 Different types of burrs obtained during milling (from Chern [9]) passes to analyze burr accumulation. The height difference between both cutting edges is measured regularly using a dial gauge. The regular measurement aims to update the vertical offset of both cutting edges, ensuring an accurate uncut chip thickness. The burr accumulation study is avoided for the highest uncut chip thickness (i.e., $h=150 \mu \mathrm{m}$ ). This is because the camera is required to be adjusted after each pass, caused by a greater depth.

2.2 Burr Topography Measurement. An in-line laser profilometer, Keyence model LJ-V7060, is set in situ to scan the burrs with an optimized measurement repeatability of $0.4 \mu \mathrm{m}$ along the perpendicular direction and $5 \mu \mathrm{m}$ along the longitudinal direction. The linearity is about $\pm 0.1 \%$ of the full scale. The overall accuracy of the sensor is estimated to be approximately $1.9 \mu \mathrm{m}$ in the perpendicular direction and $6.5 \mu \mathrm{m}$ in the longitudinal direction. The laser is installed on the $Z$-axis after each pass and a scan is performed by moving the $Y$-axis, as shown in Fig. 8(a). Each increment of the linear encoder triggers a laser scan and generates a profile. The step between two laser profiles is $8 \mu \mathrm{m}$ while the data interval along the laser line reaches $20 \mu \mathrm{m}$. The scanning setup is presented in Figs. 8(b)-8(d). Régnier et al. [7] provide an animation of the whole procedure. A complete scan of the $4 \mathrm{~mm}$ long exit edge is performed and then $0.5 \mathrm{~mm}$ from both sides are removed to obtain $3 \mathrm{~mm}$ of the scan, as presented in Figs. 2(c) and $2(d)$. The reason of maintaining a $3 \mathrm{~mm}$ profile is to avoid any possible edge effect. A total amount of 375 profiles are then analyzed to characterize burr formation modes and criteria.

2.3 Work Material and Cutting Conditions. The work material used in the study is a hypoeutectic cast aluminum alloy ENAC-AlSi $\mathrm{Mg}_{0.3}+0.5 \mathrm{Cu} \quad\left(\mathrm{AlSi}_{7} \mathrm{Mg}_{0.3}\right.$ standardized in $\mathrm{NF}$ EN1706 [15], with $0.5 \% \mathrm{Cu}$ added), with a T7 heat treatment, used to produce engine cylinder heads, with the chemical composition described in Table 1.

The tool holder used during the experiment is fully customized by $\mathrm{AIF}^{\circledR}$. All the inserts are uncoated tungsten carbides. They are produced by $\mathrm{ARNO}^{\circledR}$ (ref. SXCCN 2020M21-A) and modified by an edge-sharpening company to obtain the required geometries for the experiment. Each edge is prepared using a tribofinishing (smuritropy) machine Pardus 4H20T2S with abrasive media HAR24. During the preparation, a three-dimensional optical measurement machine Alicona InfiniteFocus SL accompanied with a $10 \times$ objective is used to measure the obtained edge radius on a regular basis. This ensures a homogeneous cutting edge and minimizes the impact on rake and clearance faces during the preparation.

A 2 deg inclination angle is set for each insert to avoid lateral burr formation visible on the camera. The specifications of the inserts and the cutting conditions are presented in Table 2.

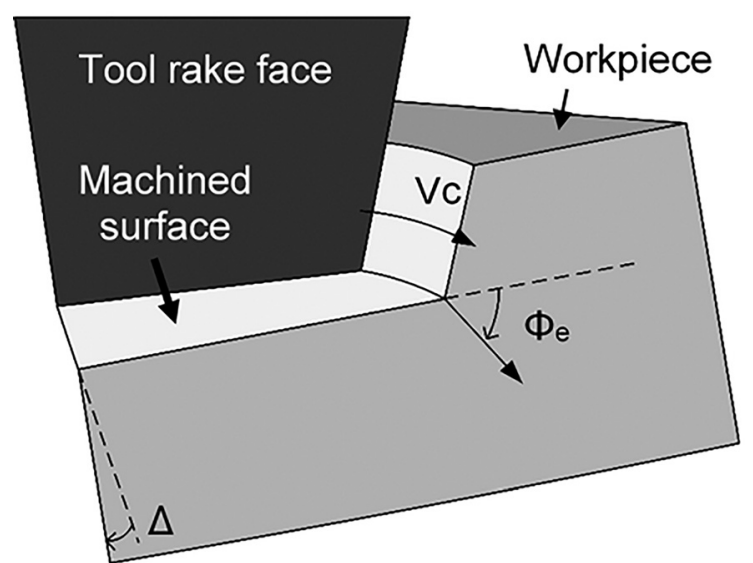

Fig. 5 Definitions of the in-plane exit angle and wedge angle (adapted from Hashimura et al. [17]) 


\section{$V_{c 1}:$ Cutting experiment speed \\ $\mathrm{V}_{\mathrm{c} 2}$ : Deburring speed}
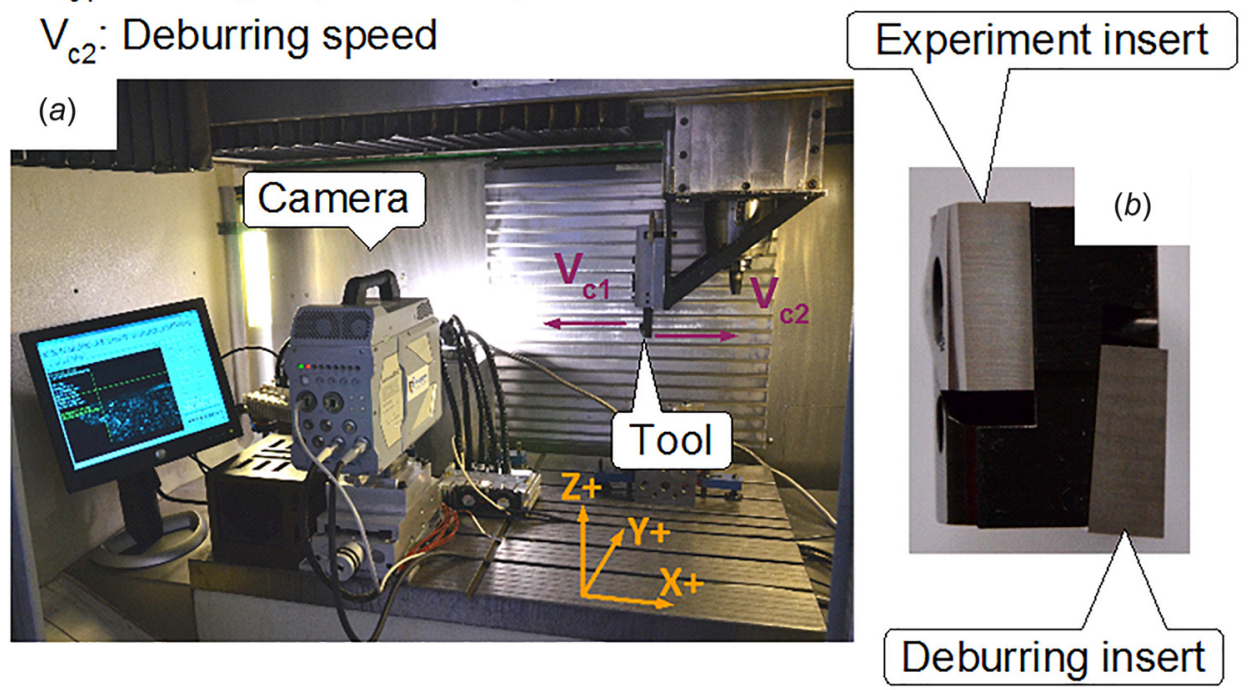

(c)

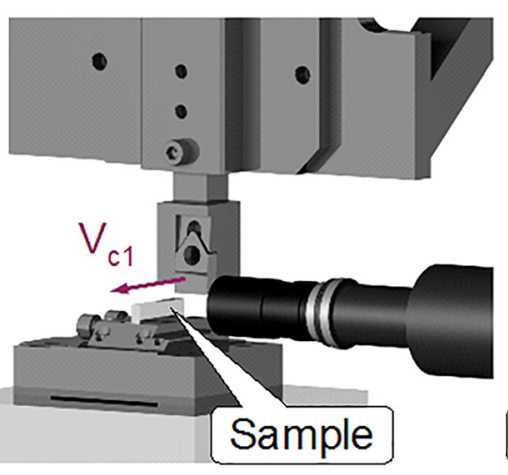

Cutting experiment

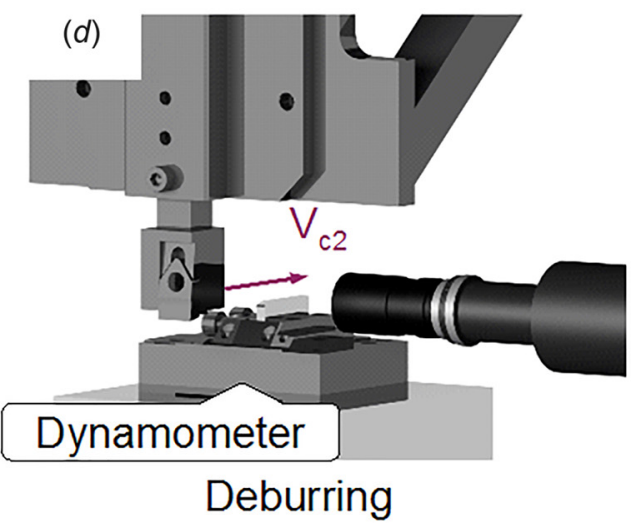

Fig. 6 Experimental setup of the cutting tests using high speed imaging system

Burr accumulation

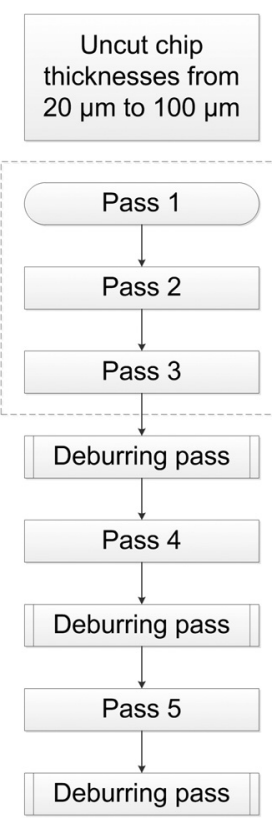

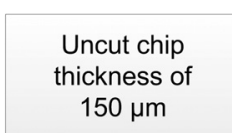

$150 \mu \mathrm{m}$

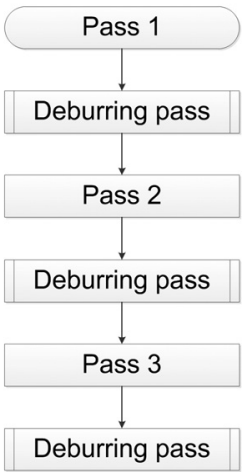

Deburring pass

Fig. 7 Experimental sequence of cutting tests

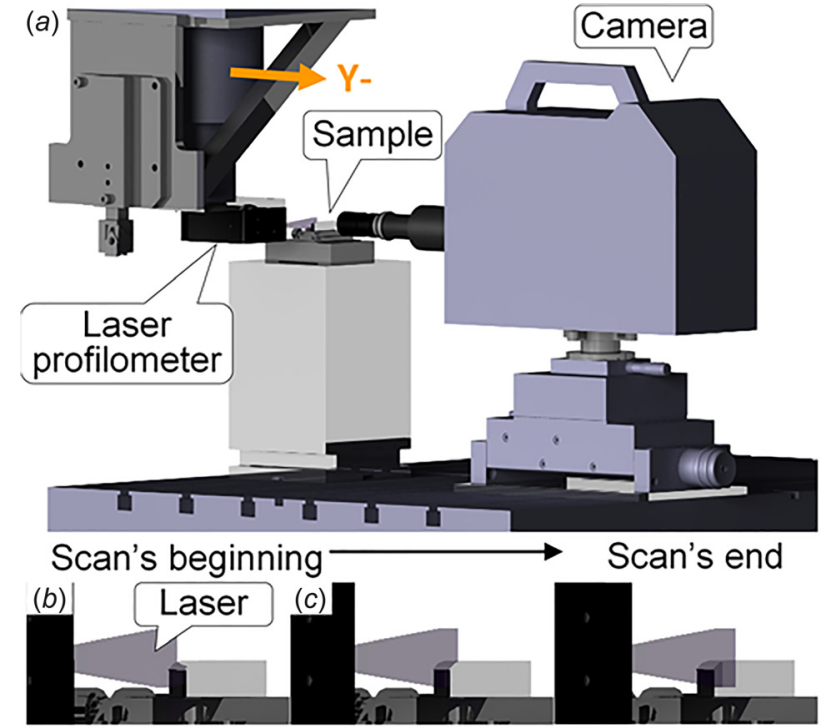

Fig. 8 Burr scanning setup

It is worth noting that positive $(10 \mathrm{deg})$, negative $(-10 \mathrm{deg})$ and null $(0 \mathrm{deg})$ rake angles are investigated. This is because the two last geometries can be found in polycrystalline diamond (PCD) milling cutters for machining aluminum alloys as opposed to carbide cutters, where mainly positive rake angles are used. 
Table 1 Work material's chemical composition (in wt \%)

\begin{tabular}{lccccccc}
\hline \hline $\mathrm{Si}$ & $\mathrm{Fe}$ & $\mathrm{Cu}$ & $\mathrm{Mn}$ & $\mathrm{Mg}$ & $\mathrm{Zn}$ & $\mathrm{Ti}$ & Other \\
\hline $6.5-7.5$ & $<0.19$ & $\approx 0.50$ & $<0.10$ & $0.25-0.45$ & $<0.07$ & $0.08-0.25$ & 0.10 \\
\hline \hline
\end{tabular}

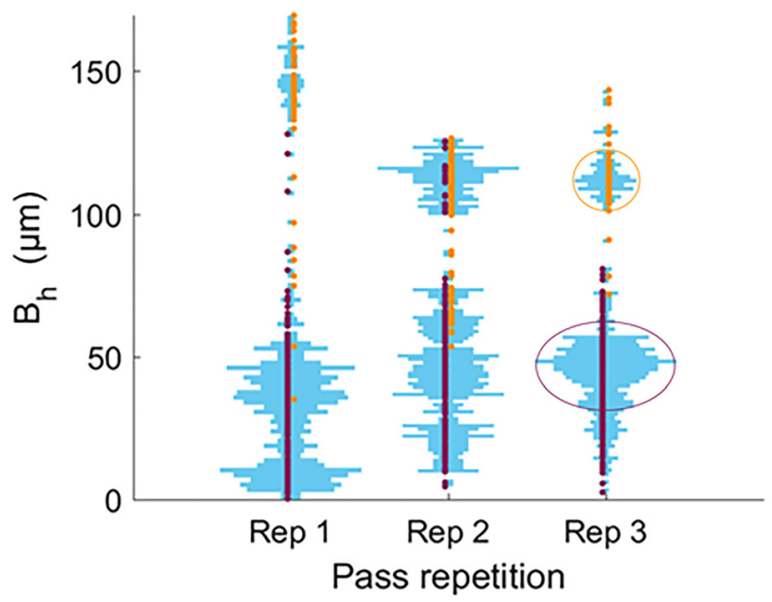

One-sigma confidence range of $\mathrm{B}_{h}$ without chamfer

One-sigma confidence range of $\mathrm{B}_{\mathrm{h}}$ with chamfer

Fig. 9 Description of the one-sigma confidence range selection for $B_{\mathrm{h}}$ with and without chamfer

\section{Application of Principal Components Analysis and Discussion}

3.1 Data Selection and Principal Component Analysis Application. Since the statistical analysis is carried out on a considerable amount of profiles and that their distribution appears to be widespread in most of the cases, specific data are selected. A violin plot, which displays the $B_{\mathrm{h}}$ distribution of three repetitive tests from their respective scan, is presented in Fig. 9. The choice

\section{Table 2 Cutting conditions and inserts specifications}

\begin{tabular}{lc}
\hline \hline Parameter & Value \\
\hline Tool material & HW-K20 \\
General surface roughness & 0.8 \\
of the rake face, $R$ (a $(\mu \mathrm{m})$ & 120 \\
Cutting speed, $V_{\mathrm{c}}(\mathrm{m} / \mathrm{min})$ & \\
Uncut chip thickness, $h(\mathrm{~mm})$ & $0.02 ; 0.03 ; 0.04 ; 0.05 ; 0.07 ; 0.10$ and 0.15 \\
Width of cut, $b(\mathrm{~mm})$ & 4 \\
Edge inclination, $\lambda_{\mathrm{s}}(\mathrm{deg})$ & 2 \\
Rake angle, $\gamma_{\mathrm{o}}(\mathrm{deg})$ & $-10 ; 0$ and 10 \\
Clearance angle, $\alpha_{\mathrm{o}}(\mathrm{deg})$ & 10 \\
Edge radius, $r_{\beta}(\mu \mathrm{m})$ & 10 and 20 \\
\hline \hline
\end{tabular}

of using each criterion average value and its corresponding onesigma confidence range, described in the figure, is made to provide good descriptors in a statistical point of view.

To correlate burr morphology criteria with cutting parameters, the latter are included into the statistical analysis matrix. The height of burrs with or without chamfer is taken into account separately during the data analysis as described in Ref. [7]. Hence, the 13 criteria, forming the PCA matrix for a total of 114 trials, are:

- Tool geometry: $r_{\beta}, \gamma$

- Cutting parameters: $h$, burr accumulation pass (pass 1,2 or 3 without deburring)

- Burr geometrical criteria: burr with chamfer proportion, average $B_{\mathrm{h}}$ with chamfer, average $B_{\mathrm{h}}$ without chamfer, average $C_{\mathrm{d}}$, average $C_{\mathrm{h}}$, one-sigma confidence range of $B_{\mathrm{h}}$ with chamfer, one-sigma confidence range of $B_{\mathrm{h}}$ without chamfer, one-sigma confidence range of $C_{\mathrm{d}}$, one-sigma confidence range of $C_{\mathrm{h}}$.

The chamfer angle $\Gamma_{\mathrm{c}}$ is not included in the matrix because it is linked geometrically from $C_{\mathrm{d}}$ and $C_{\mathrm{h}}$.

3.2 Analysis and Results Interpretation. The PCA analysis starts by choosing the number of principal axes to analyze. This is conducted using a scree plot, a graphic representation, which sorts the principal axes with respect to their variability (ratio between the axis variance and the total variance) or their eigenvalue (representing the variance of the axis). A cumulative curve shows the

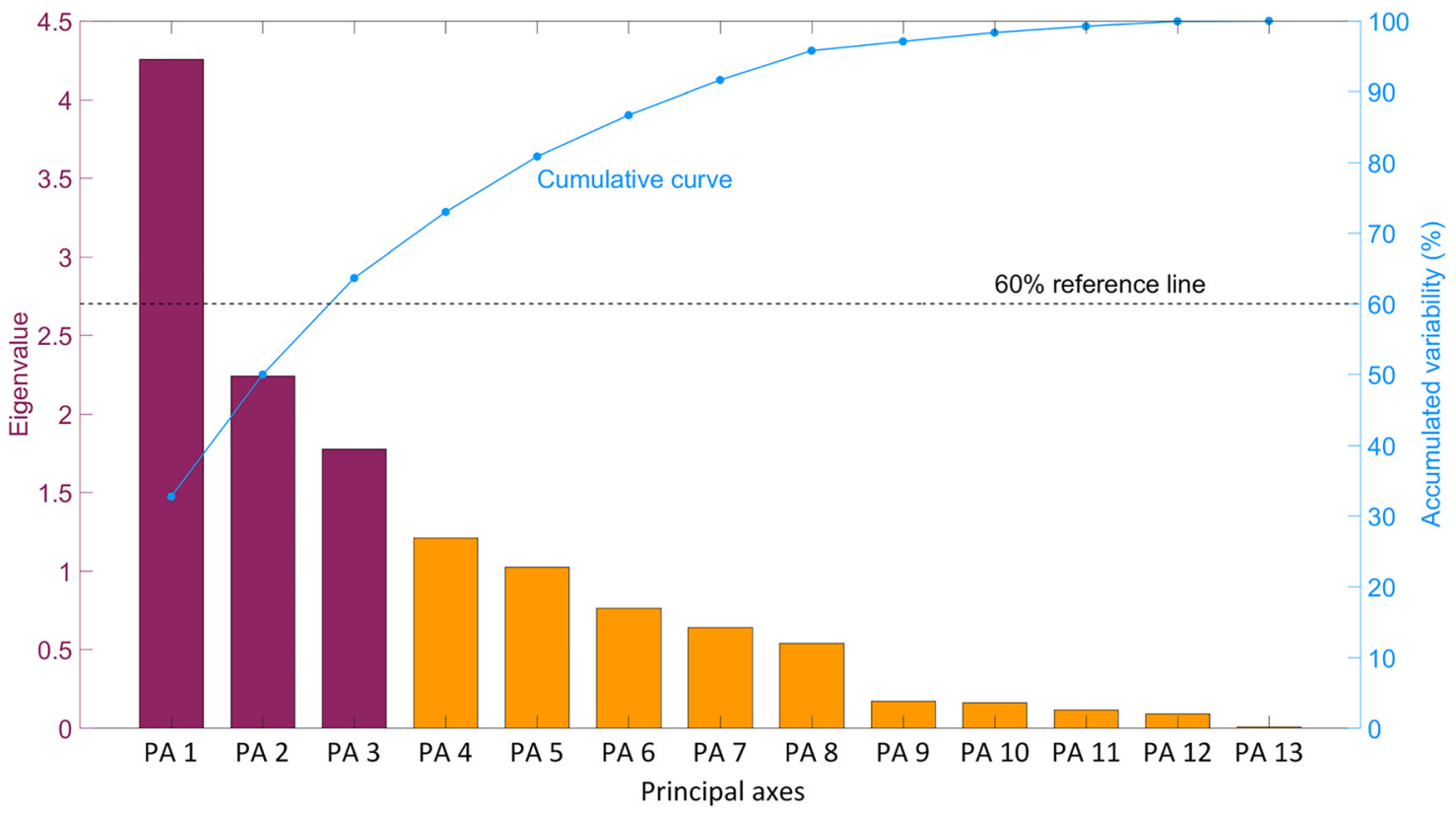

Fig. 10 Scree plot 


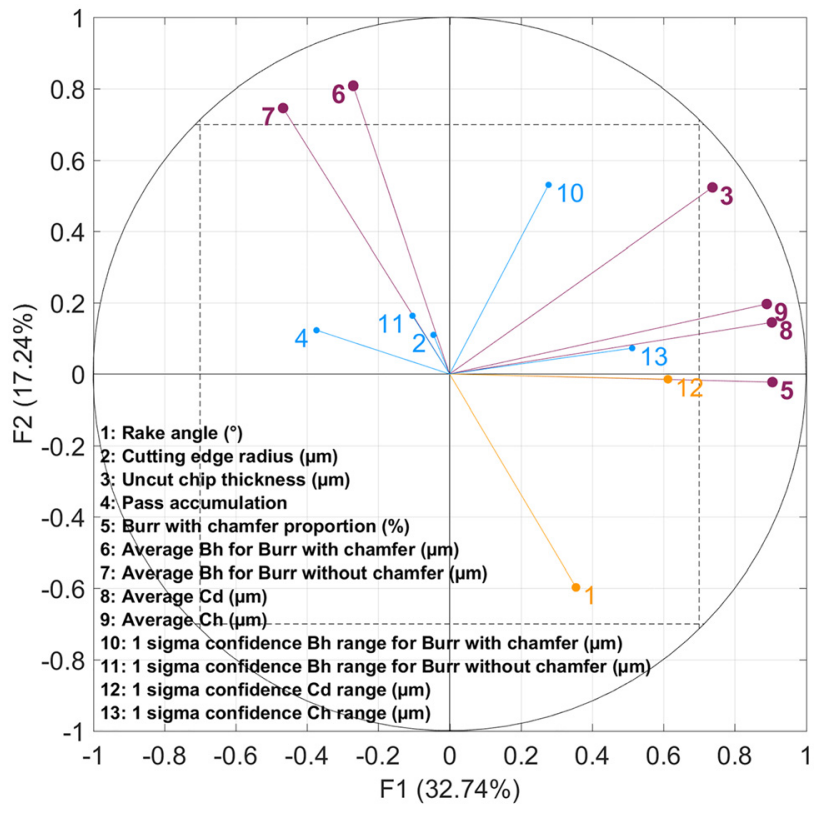

Fig. 11 Correlation circle for the first and second axes

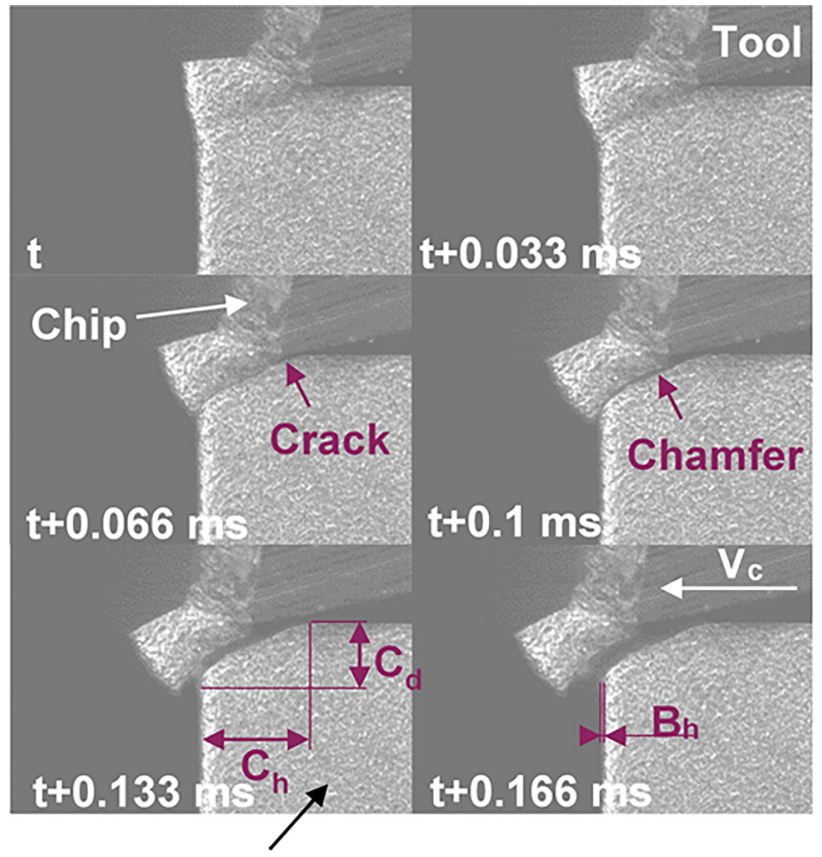

Sand blasted surface

$y=10^{\circ} ; r_{\beta}=10 \mu \mathrm{m} ; \mathrm{h}=0.15 \mathrm{~mm}$

Fig. 13 Formation of burr with chamfer

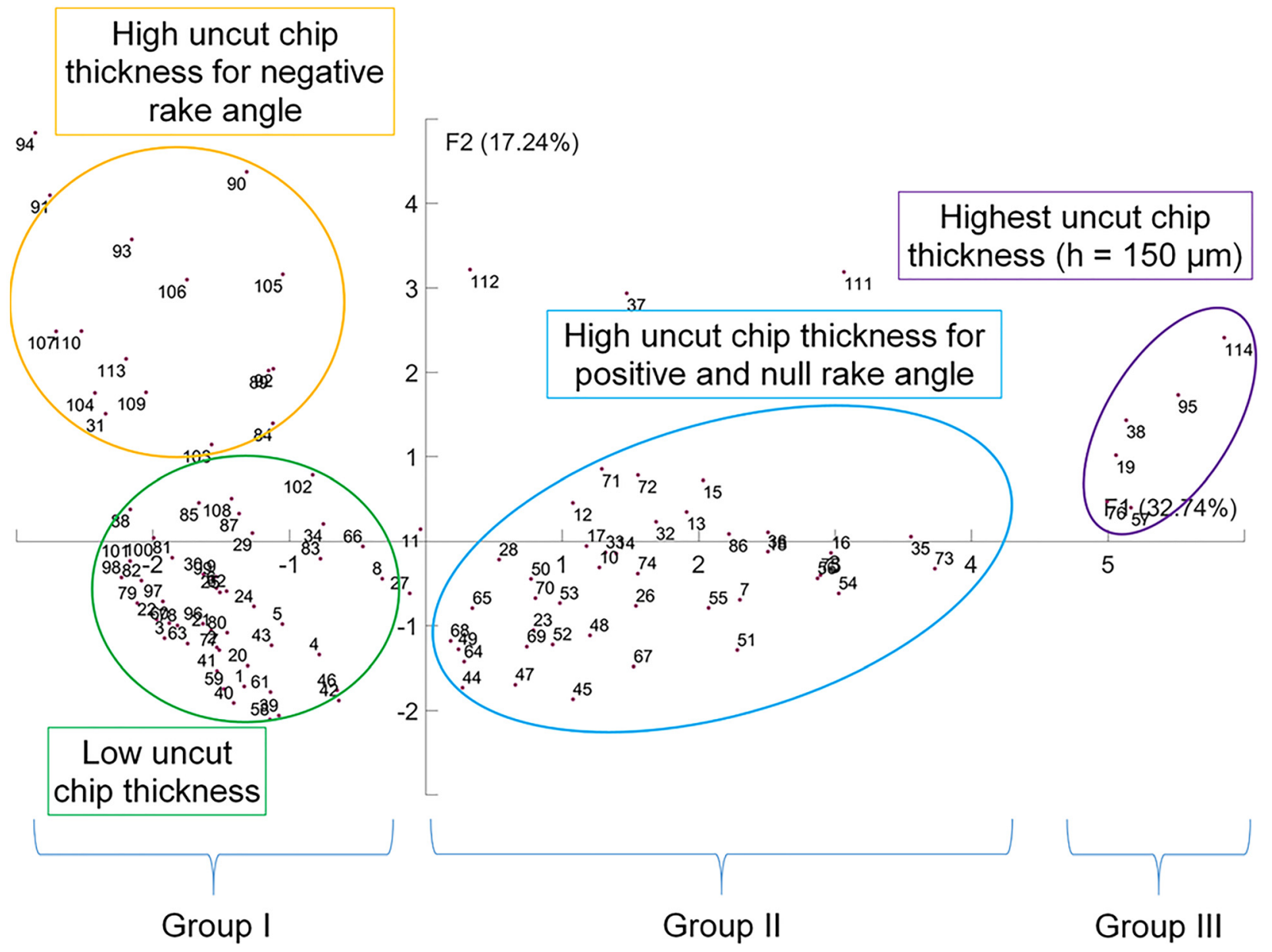

Fig. 12 Observations contribution graphic for the first and second axes 


\section{Burr without chamfer}

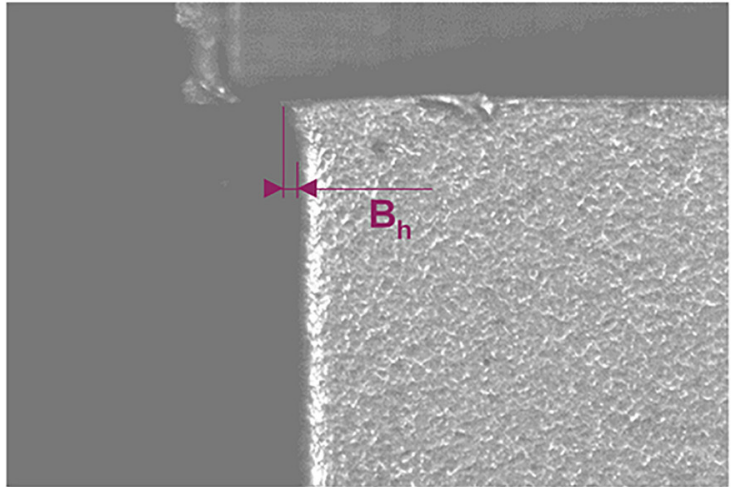

$Y=0^{\circ} ; r_{\beta}=20 \mu \mathrm{m} ; \mathrm{h}=0.03 \mathrm{~mm}$

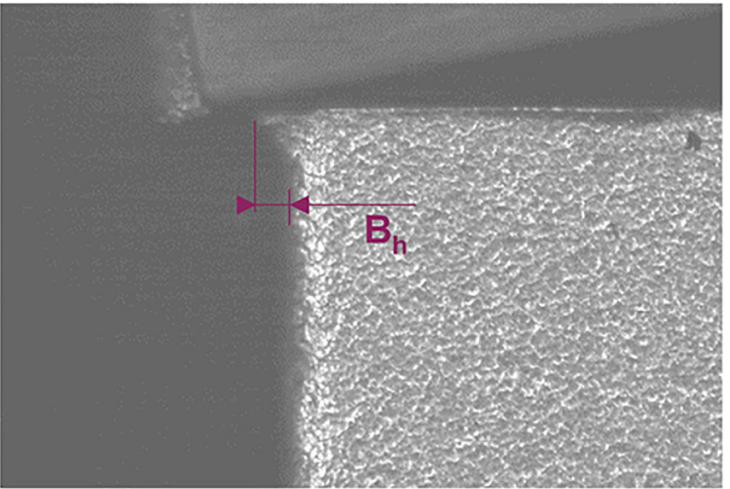

$Y=-10^{\circ} ; r_{\beta}=20 \mu \mathrm{m} ; \mathrm{h}=0.03 \mathrm{~mm}$

Burr with chamfer

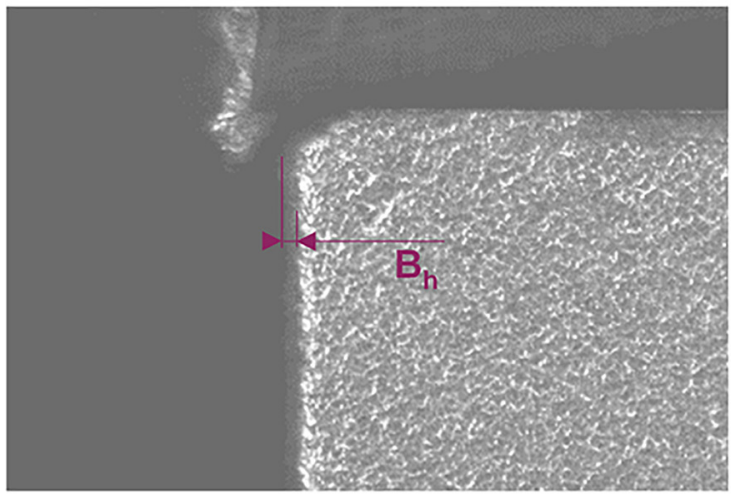

$Y=10^{\circ} ; r_{\beta}=10 \mu \mathrm{m} ; \mathrm{h}=0.05 \mathrm{~mm}$

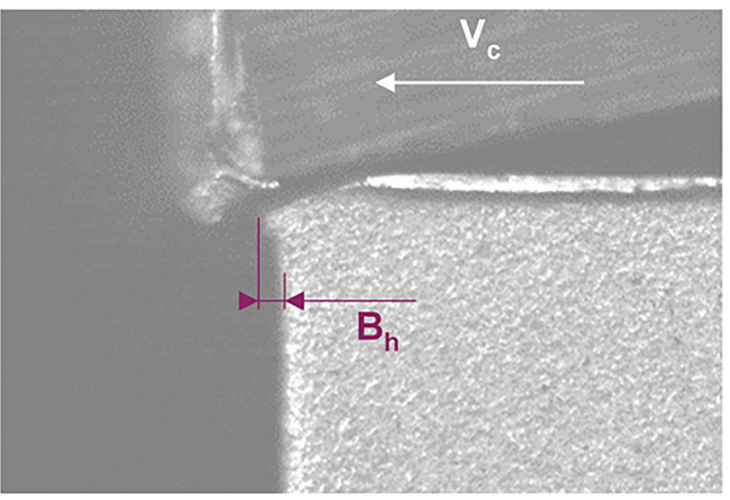

$Y=-10^{\circ} ; r_{\beta}=10 \mu \mathrm{m} ; \mathrm{h}=0.05 \mathrm{~mm}$

Fig. 14 Comparison between both burr types generated with different rake angles

variability accumulated by the axes. Generally, after a certain number of axes, the cumulative curve slope changes significantly. The principal axes after the abrupt change of slope are omitted. From the scree plot presented in Fig. 10, no significant change of slope is visible. Consequently, the arbitrary choice of analyzing at least $60 \%$ of the variability has been made. Therefore, the three first principal axes are analyzed, since they represent $63.7 \%$ of the variability. Furthermore, the marginality of the variables contributing to the other axes confirms this choice.

The first analysis that should be carried out is the interpretation of the correlation circles. These circles help to determine the variables activated for each axis. The first correlation circle shown in Fig. 11 represents the variables activation for the first and second principal axes, respectively, accounting for about $50 \%$ of the total experimental plan variability.

3.2.1 First Principal Axis Interpretation (32.7\% of the Variability). The analysis provides four correlated activated variables and one "almost active" supplementary variable:

- Burr with chamfer proportion: $19.3 \%$ (number 5)

- Average $C_{\mathrm{d}}: 19.2 \%$ (number 8 )

- Average $C_{\mathrm{h}}: 18.6 \%$ (number 9 )

- Uncut chip thickness $h$ (cutting parameter): $12.8 \%$ (number 3)

- One-sigma confidence range of $C_{\mathrm{d}}: 8.8 \%$ (number 12 )

The analysis of the variables contribution and square cosine $\left(\cos ^{2}\right)$ for the first axis rejects the influence of the chamfer depth (one-sigma confidence range). Finally, the observations contribution graphic presented in Fig. 12 show three groups along the first axis. Group I is situated close to the zero/negative section of the axis. This group comprises the observations of low uncut chip thickness $(20 \mu \mathrm{m}$ to $50 \mu \mathrm{m})$ and of negative rake angle. Group II is situated close to the zero/positive section of the axis, representing the observations of high uncut chip thickness $(70 \mu \mathrm{m}$ to $100 \mu \mathrm{m})$

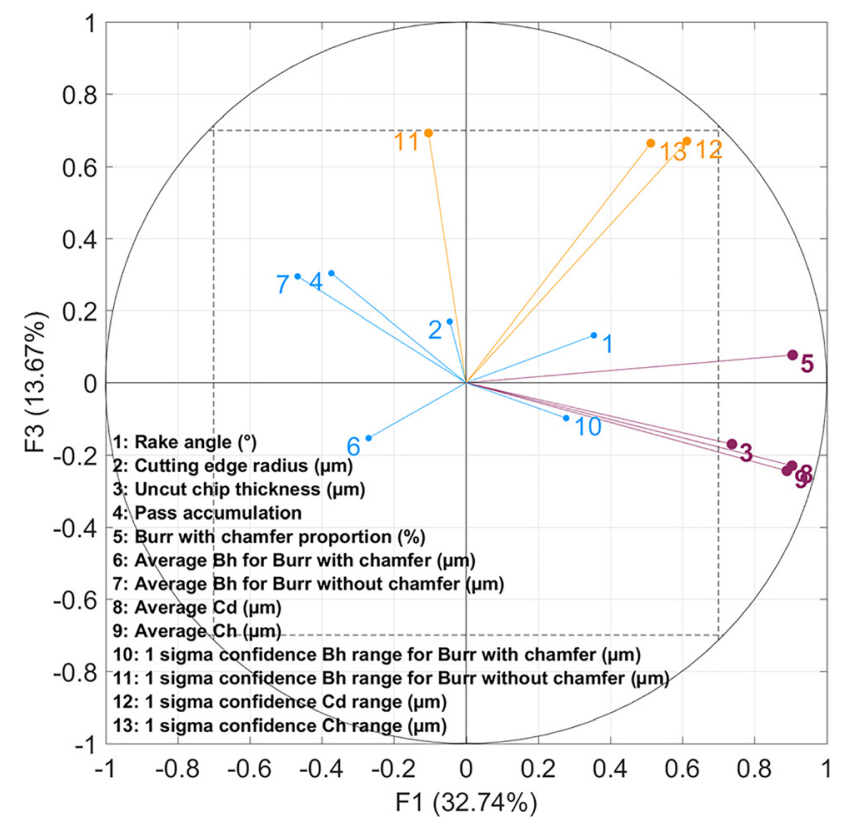

Fig. 15 Correlation circle for the first and third axes 


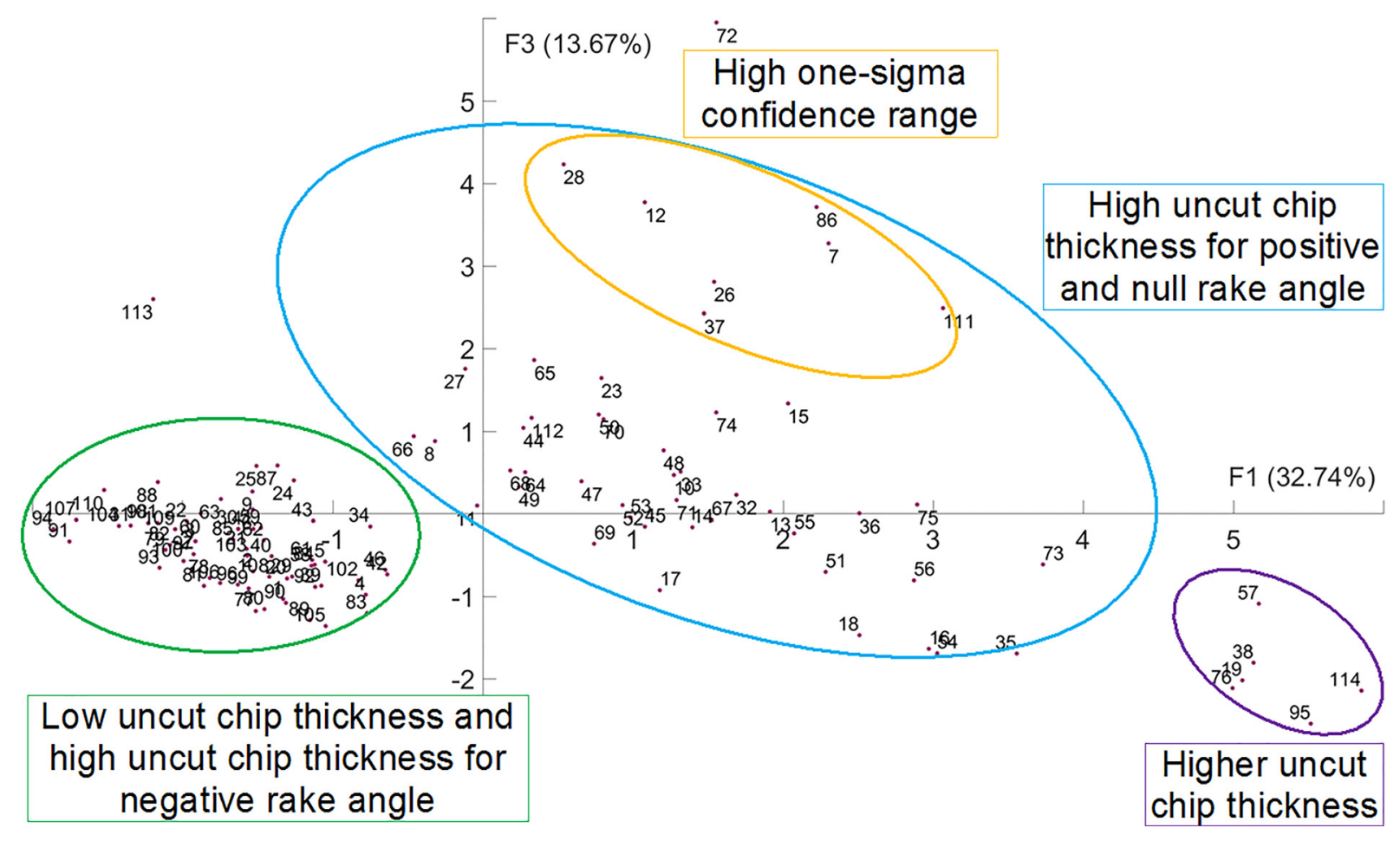

Fig. 16 Observations contribution graphic for the first and third axes

for positive and null rake angle. Finally, group III represents the observations of relatively higher uncut chip thickness $(150 \mu \mathrm{m})$. It is situated in the far positive section of the axis. This analysis allows to note that observations with high uncut chip thickness contribute the most to the axis.

The correlation between the uncut chip thickness evolution and the burr with chamfer proportion has already been observed in the previous study [7]. This can be explained by the stress triaxiality generated during the cut and especially at the transition between steady-state cutting and burr initiation. As presented in the introduction, an increase of the uncut chip thickness widens a combined shear/tension stress area around the cutting edge. Therefore, fracture strain decreases, which increases the appearance of burr with chamfer due to crack propagation in the workpiece region underneath the tool cutting edge (cf. Fig. 13).

The average chamfer angle $\left(\Gamma_{\mathrm{c}}\right)$ along the exit edge of the workpiece has been observed to be quasi-constant regardless of the uncut chip thickness (for a same tool geometry). This behavior implies that when the chamfer depth increases, the chamfer height increases. As mentioned previously, a higher uncut chip thickness leads to a wider combined shear/tension stress area. Hence, the wider shear/tension zone gives rise to an earlier reach to the exit surface. This, in turn, initiates fracture earlier, resulting in a higher burr chamfer height and depth.

3.2.2 Second Principal Axis Interpretation (17.2\% of the Variability). As shown, the correlation circle in Fig. 11, the second axis is created by two active variables correlated between them and one "almost active" anti-correlated variable:

- Average $B_{\mathrm{h}}$ for burr with chamfer: $29.1 \%$ (number 6)

- Average $B_{\mathrm{h}}$ for burr without chamfer: $24.8 \%$ (number 7)

- Rake angle $\gamma$ (tool geometry): $15.9 \%$ (number 1)

Using the same analysis procedure applied to the first axis, an analysis for the second axis is performed with the choice of retaining the tool rake angle as an active variable. The analysis shows that this axis is mainly influenced by negative rake angle observations. During a cut with a low rake angle, especially if it is negative, more compression occurs. Therefore the burr root depth increases then more material volume bends. This mechanism occurs during both burr type formation, as it can be observed in Fig. 14.

3.2.3 Third Principal Axis Interpretation (13.7\% of the Variability). The third axis is driven by three "almost active" variables as presented in Fig. 15. These variables are the following geometrical parameters:

- One-sigma confidence range of burr without chamfer: $27 \%$ (number 11)

- One-sigma confidence range of $C_{\mathrm{d}}: 25.3 \%$ (number 12)

- One-sigma confidence range of $C_{\mathrm{h}}: 24.9 \%$ (number 13 )

The observation contribution presented in Fig. 16 does not provide any new information on the correlation between the specific group of observations with high range of geometrical characteristics and the cutting parameters. The range evolution seems random.

The active variables are not correlated with any controlled parameter evaluated in this study. This implies that the range of the geometrical parameters does not depend on the cutting parameters. Some tests were repeated (not presented here) and show a variability on burr dimensions ranges. Moreover, with the same cutting conditions, two types of burr are randomly distributed along the exit edge of the workpiece. A hypothesis that the material microstructure heterogeneity influences the burr geometrical characteristics ranges is made. A complementary investigation comparing burr geometrical characteristics ranges with respect to the material microstructure (secondary dendrite arm spacing or $\mathrm{Si}$ particles proportion for example) could be interesting to be carried out in future.

\section{Conclusion}

In this study, a highly developed experimental methodology is proposed to observe the burr formation, to scan precisely the exit edge burr morphology without any sample unclamping and to quantify the distribution of different geometrical criteria. PCA is used as a tool to explain the contribution of cutting parameters 
and tool geometry on several exit burr characteristics. Those characteristics are caused by two different mechanisms.

Results show that uncut chip thickness has a strong effect on burr with/without chamfer formation. A high uncut chip thickness gives rise to a higher tendency to the formation of burr with chamfer. Furthermore, it modifies the chamfer geometry: both chamfer depth and height grow with the increase of the uncut chip thickness. This can be explained by the decrease of the stress triaxiality, hence strain at fracture, at the workpiece region situated ahead of the tool cutting edge during burr formation.

A relation between the tool rake angle and the height of both types of burrs is confirmed. The lower the rake angle is, the lower the height of burrs with and without chamfer is. The use of negative rake angle amplifies this effect. This relation is explained by the decrease of the stress triaxiality, which increases the strain at fracture of the work material.

Finally, the range of the burrs geometrical characteristics do not seem to be driven by any cutting parameter nor any tool geometry. However, in the future, it could be advisable to include material microstructure as a controlled parameter and to analyze its influence on the range of the burrs geometrical characteristics.

\section{Acknowledgment}

The authors would like to thank Pierre Naisson from CERN, and Vincent Moreau from CETIM for their advice and help on edge preparation. The authors would also like to show their gratitude to Martine Tillier for her help on Principal Components Analysis.

\section{Funding Data}

- The present study was conducted using materials financially supported by the Région Bourgogne Franche-Comté.

\section{References}

[1] Gillespie, L. K., and Blotter, P. T., 1976, "The Formation and Properties of Machining Burrs," J. Eng. Ind., 98(1), pp. 66-74.

[2] Pekelharing, A. J., 1978, "Exit Failure in Interrupted Cutting," Ann. CIRP, 27(1), pp. 5-10.

[3] Iwata, K., Ueda, K., and Okuda, K., 1982, "Study of Mechanism of Burrs Formation in Cutting Based on Direct SEM Observation," J. Jpn. Soc. Precis. Eng., 48(4), pp. 510-515.

[4] Hashimura, M., Chang, Y. P., and Dornfeld, D., 1999, "Analysis of Burr Formation Mechanism in Orthogonal Cutting," ASME J. Manuf. Sci. Eng., 121(1), pp. $1-7$.

[5] ISO, 2000, "Technical Drawings-Edges of Undefined Shape-Vocabulary and Indications," International Organization for Standardization, Geneva, Switzerland, Standard No. ISO 13715:2000.

[6] Schäfer, F., Brauner, H. U., and Breuninger, F., 1975, "Entgraten: Theorie, Verfahr, Anlagen," Krausskopf, Mainz.

[7] Régnier, T., Fromentin, G., Marcon, B., Outeiro, J., D’Acunto, A., Crolet, A. and Grunder, T., 2018, "Fundamental Study of Exit Burr Formation Mechanisms During Orthogonal Cutting of AlSi Aluminium Alloy," J. Mater. Process. Technol., 257, pp. 112-122.

[8] Abushawashi, Y. M., 2013, "Modeling of Metal Cutting as Purposeful Fracture of Work Material," Ph.D. thesis, Michigan State University, East Lansing, MI.

[9] Chern, G.-L., 2006, "Experimental Observation and Analysis of Burr Formation Mechanisms in Face Milling of Aluminum Alloys," Int. J. Mach. Tools Manuf., 46(12-13), pp. 1517-1525.

[10] Kishimoto, W., 1981, "Study of Burr Formation in Face Milling-Conditions for the Secondary Burr Formation,” Bull. Jpn. Soc. Prec. Eng., 15(1), pp. 51-52.

[11] Bourlet, C., Fromentin, G., Harika, E., and Crolet, A., 2016, "Analysis and Modeling of Burr Formation During the Plane Milling of Cast Aluminium Alloy Using PCD Tools," ASME J. Manuf. Sci. Eng., 138(8), p. 81010.

[12] Abdi, H., and Williams, L. J., 2010, "Principal Component Analysis," Wiley Interdiscip. Rev. Comput. Stat., 2(4), pp. 433-459.

[13] Lorenz, G., 1989, "Principal Component Analysis in Technology," CIRP Ann., 38(1), pp. 107-109.

[14] Dubey, A. K., and Yadava, V., 2008, "Multi-Objective Optimization of Nd YAG Laser Cutting of Nickel-Based Superalloy Sheet Using Orthogonal Array With Principal Component Analysis," Opt. Lasers Eng., 46(2), pp. 124-132.

[15] NF EN1706, 2010, "Aluminium and Aluminium Alloys-Castings-Chemical Composition and Mechanical Properties," Association Française de Normalisation, France, Standard No. NF EN 1706:2010.

[16] da Silva, L. C., da Mota, P. R., da Silva, M. B., Ezugwu, E. O., and Machado, Á. R., 2015, "Study of Burr Behavior in Face Milling of PH 13-8 Mo Stainless Steel," CIRP J. Manuf. Sci. Technol., 8, pp. 34-42.

[17] Hashimura, M., Hassamontr, J., and Dornfeld, D. A., 1999, "Effect of In-Plane Exit Angle and Rake Angles on Burr Height and Thickness in Face Milling Operation,” ASME J. Manuf. Sci. Eng., 121(1), pp. 13-19. 